\title{
Climatology and seasonality of upper ocean salinity: a three- dimensional view from argo floats
}

\author{
Ge Chen ${ }^{1,2}(-) \cdot$ Lin Peng $^{1} \cdot$ Chunyong Ma ${ }^{1,2}$
}

Received: 3 May 2016 / Accepted: 26 May 2017 / Published online: 9 June 2017

(c) The Author(s) 2017. This article is an open access publication

\begin{abstract}
Primarily due to the constraints of observation technologies (both field and satellite measurements), our understanding of ocean salinity is much less mature compared to ocean temperature. As a result, the characterizations of the two most important properties of the ocean are unfortunately out of step: the former is one generation behind the latter in terms of data availability and applicability. This situation has been substantially changed with the advent of the Argo floats which measure the two variables simultaneously on a global scale since early this century. The first decade of Argo-acquired salinity data are analyzed here in the context of climatology and seasonality, yielding the following main findings for the global upper oceans. First, the six well-defined "salty pools" observed around $\pm 20^{\circ}$ in each hemisphere of the Pacific, Atlantic and Indian Oceans are found to tilt westward vertically from the sea surface to about $600 \mathrm{~m}$ depth, forming six saline cores within the subsurface oceans. Second, while potential temperature climatology decreases monotonically to the bottom in most places of the ocean, the vertical distribution of salinity can be classified into two categories: A doublehalocline type forming immediately above and below the local salinity maximum around $100-150 \mathrm{~m}$ depths in the tropical and subtropical oceans, and a single halocline type existing at about $100 \mathrm{~m}$ depth in the extratropical oceans. Third, in contrast to the midlatitude dominance for
\end{abstract}

Ge Chen

gechen@ouc.edu.cn

1 Department of Marine Technology, College of Information Science and Engineering, Ocean University of China, 238 Songling Road, Qingdao 266100, China

2 Laboratory for Regional Oceanography and Numerical Modeling, Qingdao National Laboratory for Marine Science and Technology, Qingdao, China temperature, seasonal variability of salinity in the oceanic mixed layer has a clear tropical dominance. Meanwhile, it is found that a two-mode structure with annual and semiannual periodicities can effectively penetrate through the upper ocean into a depth of $\sim 2000 \mathrm{~m}$. Fourth, signature of Rossby waves is identified in the annual phase map of ocean salinity within $200-600 \mathrm{~m}$ depths in the tropical oceans, revealing a strongly co-varying nature of ocean temperature and salinity at specific depths. These results serve as significant contributions to improving our knowledge on the haline aspect of the ocean climate.

Keyword · Ocean salinity · Argo floats · Climatology · Annual cycle $\cdot$ Semiannual cycle

\section{Introduction}

Along with temperature and pressure, salinity is one of the three key variables for determining the seawater density. The importance of density in ocean dynamics cannot be over emphasized, because small changes of it will result in spatial variations in pressure at a given depth, which in turn drive the ocean circulation and vertical convection at all scales (Riser et al. 2008). Meanwhile, salinity can significantly affect ocean-atmosphere exchanges in the tropics through the barrier layer process (e.g., de Boyer Montégut et al. 2007). Salinity is also an important factor in determining many aspects of the chemistry of seawater and of biological processes within it (Pawlowicz 2013), and thus serves as one of the "bridge" variables in connecting the geophysical and biogeochemical states of the ocean. In addition, given that ocean salinity is a better observed variable than evaporation and precipitation, the concept of 
using the ocean as a rain gauge for the global water cycle has been proposed (e.g., Yu 2011). Meanwhile, salinity is also a key parameter in modelling the large scale seasonal freezing and melting of sea ice in polar and subpolar regions. The apparent connection between ocean salinity and the global water cycle brings it into the center of the climate change stage. As evidenced in Durack et al. (2012), ocean salinity patterns express an identifiable fingerprint of an intensifying water cycle at a rate of $8 \pm 5 \%$ per degree of surface warming. Using near-surface salinity as the Nature's rain gauge, Terray et al. (2012) reported a discernible human influence on the late twentieth-century evolution of the tropical marine water cycle. A later work by Chen and Tung (2014) also suggested that the slowdown of the twenty-first-century surface warming is mainly caused by heat transported to deeper layers in the Atlantic and the Southern Oceans initiated by a recurrent salinity anomaly in the subpolar North Atlantic. However, the use of salinity as a proxy for the impact of hydrological cycle encountered a mismatch of time scales between the ocean and the atmosphere (Bingham et al. 2012), and efforts to detect the long-term response of "rich get richer" in sparse surface observations of rainfall and evaporation remain ambiguous (Durack et al. 2012). For all these reasons, salinity in terms of both climatology and variability naturally becomes one of the most needed variables in ocean and climate sciences.

Despite of the urgent need for continuing measurements of high quality salinity data over the global ocean, their actual availability is about an order of magnitude less than the temperature data (Lorbacher et al. 2006; Giglio et al. 2013). Our basic knowledge about the global sea surface/subsurface salinity is derived from the World Ocean Atlas 2005, a careful compilation of most available in situ oceanographic data collected over time (Boyer et al. 2005). This situation began to change early this century thanks to the operational functioning of two revolutionary salinity observation systems: (1) the Argo array now consisting of over 3000 individual floats started deployment in 2001 (Roemmich et al. 2009; Riser et al. 2016); (2) two dedicated satellites including the soil moisture ocean salinity (SMOS) mission launched in November 2009 (Boutin et al. 2012), and the Aquarius/SAC-D mission launched in June 2011 (Lagerloef et al. 2008; see also the special issue on Aquarius and SMOS in Journal of Geophysical ResearchOceans, 2014). The two systems are highly complementary as they measure the interior and surface salinity of the ocean, respectively.

Continued efforts have been devoted to the investigation of ocean salinity using Argo data in the past decade. Roemmich and Gilson (2009) compared the annual cycles in salinity of Argo data to the World Ocean Atlas, and to the National Oceanography Center air-sea flux climatology, the Reynolds sea surface temperature (SST) product, and
AVISO satellite altimetric height. These products are consistent with Argo data on hemispheric and global scales, but show considerable regional differences that may either point to systematic errors in the datasets or their syntheses, to physical processes, or to temporal variabilities. Using over 1.6 million profiles of salinity, potential temperature, and neutral density from historical archives and the Argo floats, Durack and Wijffels (2010) studied the fifty-year trends in global ocean salinities and their relationship to broad-scale warming. Salinity increases at the sea surface are found in evaporation-dominated regions and freshening in precipitation-dominated regions, with the spatial pattern of change strongly resembling that of the mean salinity field, consistent with an amplification of the global hydrological cycle. The seasonal variability of surface layer salinity over the global ocean was examined by Bingham et al. (2012) using a variety of in situ and reanalysis data including Argo. They find that areas with large amplitude seasonal salinity variations include the Intertropical Convergence Zone (ITCZ) of the Atlantic, Pacific and Indian Oceans, western marginal seas of the Pacific, and the Arabian Sea. Phases of surface salinity have a bimodal distribution, with most areas in the northern hemisphere peaking in March/April and in the southern hemisphere in September/ October. Using monthly gridded fields of salinity optimally interpolated from Argo and CTD observations, Kolodziejczyk and Gaillard (2012) identified two strong events of positive spiciness injection in the southeastern Pacific during the austral winters of 2007 and 2010. In a later study, they found an excess of salt flux residual at the base of the mixed layer during these same winters. Furthermore, they showed that the anomalously high-salinity injections are driven by a greater than normal latent heat loss (Kolodziejczyk and Gaillard 2013). Based on multiple sources of salinity data from Argo, ship, mooring, CTD and satellite observations as well as numerical models, the mixed layer salinity budget in the tropical Pacific Ocean was assessed (Hasson et al. 2013). They conclude that the mean spatial distribution of mixed layer salinity results from a subtle balance between surface forcing (evaporation minus precipitation), horizontal advection (at low and high frequencies) and subsurface forcing (entrainment and mixing), all terms being of analogous importance.

More recently, Qu et al. (2014) investigated the sea surface salinity (SSS) and barrier layer variability in the equatorial Pacific using available Aquarius and Argo data. Comparison between the two datasets shows essentially the same seasonal cycle in both magnitude and phase. Analysis of the Argo data further suggests that a thick barrier layer is present on the western side of the SSS front during all the period of observation, moving back and forth along the equator. By linking to Argo subsurface salinity observations and satellite derived surface forcing datasets, $\mathrm{Yu}$ 
(2014) discovered that the prominent zonal SSS front that extends across the tropical Pacific between $2^{\circ}-10^{\circ} \mathrm{N}$ is in fact the surface manifestation of a low-salinity convergence zone located within $100 \mathrm{~m}$ of the upper ocean. Moon and Song (2014) found that the seasonal SSS variability at skin layer differs regionally in their amplitude from Argo-measured salinity at $5 \mathrm{~m}$ depth, while agrees with ocean circulation model derived salinity at the top layer. The comparison suggests that different dynamics can lead to different vertical salinity stratifications locally, which explain the differences between the Aquarius observations in the first centimeter of the sea surface, the Argo measurements at the $5 \mathrm{~m}$ depth, and model's representation of the surface-layer averaged salinity.

A dramatic increase in salinity-related studies is seen in recent literature, and our knowledge on ocean salinity and its variability have been considerably improved, as mostly evidenced in several special issues or sections mentioned above. Some of the existing works are of a validation and comparison nature for different salinity datasets (e.g., Reverdin et al. 2007, 2014; Roemmich and Gilson 2009; Drucker and Riser 2014). Many others are of a regional or basin scale nature for particular surface features and their mechanisms (e.g., Delcroix et al. 2011; Singh et al. 2011; Qu et al. 2014; Yu 2014). Detailed characterizations of the overall three-dimensional (3-D) structures of global salinity climatology and variability, especially for the subsurface and interior oceans, are still far from sufficient (The CLIVAR salinity working group 2008; Riser et al. 2016). This forms the major motivation of the present research, thanks to the recent availability of the first decade-long Argo salinity measurements. The rest of the paper is organized as follows: A brief description of the Argo data and processing method is provided in Sect. 2. An eleven-year climatology of global upper ocean salinity is constructed and analyzed in Sect. 3. The 3-D amplitude and phase of the annual and semiannual cycles of ocean salinity are presented and discussed in Sects. 4 and 5, respectively. And a summary with conclusions is provided in Sect. 6 .

\section{Data and method}

Eleven years of Argo data spanning from 2004 to 2014 are used in this study. Argo floats are designed to observe largescale (seasonal and longer, thousand kilometers and larger) subsurface ocean variability globally (Roemmich et al. 2009). As the first observation system of global subsurface ocean in history and one of the main sources of in situ temperature/salinity $(T / S)$ measurements, the aim of the Argo Program is to provide simultaneous $T / S$ observations of the 0-2000 m upper ocean in near real time, thanks to its state-of-the-art spatial-temporal sampling and truly global coverage. By January 2016, there were as many as 3918 active floats disseminated around the global ocean spacing nominally at every $3^{\circ}$ of longitude and latitude with a varying vertical sampling interval (from $10 \mathrm{~m}$ between surface and $200 \mathrm{~m}$ depth, to greater than $200 \mathrm{~m}$ between 1500 and $2000 \mathrm{~m}$ depth). In this investigation, gridded Argo temperature data are obtained from the China Argo Real-Time Data Center (http://www.argo.org.cn/). There are 48 vertical layers in our dataset ranging from 5 to $1950 \mathrm{~m}$ with an interpolated spatial resolution of $1^{\circ} \times 1^{\circ}$ and temporal resolution of 1 month, respectively. One is referred to Appendix A of Chen and Wang (2016) for a detailed description of the space-time interpolation schemes for Argo data reconstruction. The technical scheme of harmonic analysis is briefly summarized below for completeness and readability.

The accumulation of continuous time series from available Argo floats has now exceeded one decade for the first time. The annual and semiannual harmonics of ocean salinity with a periodicity of $P=12$ months or $P=6$ months for a given layer can be derived through Fourier analysis of the time series $S(x, y, \mathrm{z}, t)$ at each grid point $(x, y)$ of depth $z, S(x, y, z, t)=A(x, y, z) \times \cos [2 \pi t / P+\varphi(x, y, z)]$, where $A$ is the amplitude of the seasonal component, $\varphi$ is the phase angle which determines the time when the maximum of the seasonal harmonic occurs, while $t$ varies from 0 to 132 months for the present Argo dataset. Given a complete spatiotemporal dataset of $S(x, y, z, t), A(x, y, z)$ and $\varphi(x, y, z)$ can be simultaneously retrieved and are supposed to carry full information of annual and semiannual salinity variabilities in terms of amplitude and phase for the global upper ocean. Note that the explained variance and significance test of Argo derived annual and semiannual temperatures, which are basically applicable to their counterparts in salinity and closely related to the sensitivity or robustness of the present results, can be found in Appendix B of Chen and Wang (2016).

\section{Climatology}

The global distributions of ocean salinity climatology for 2004-2014 are shown in Fig. 1. Obviously, the spatial patterns at all selected depth layers are zonally oriented with a number of semi-basin-scale maxima/minima in the subtropics. A striking feature in the top $600 \mathrm{~m}$ layers is the existence of six well-defined "salty pools" (SP) in the two hemispheres of the Pacific, Atlantic, and Indian Oceans (Fig. 1a-h). Since surface salinity is set climatologically by opposing effects of global evaporation and precipitation, river runoff in coastal regions, and ice melt and formation in polar regions, it is natural that the 6-SP distribution (Fig. 1a) is related to the net difference of these effects, especially evaporation minus precipitation $(E-P$, e.g., 

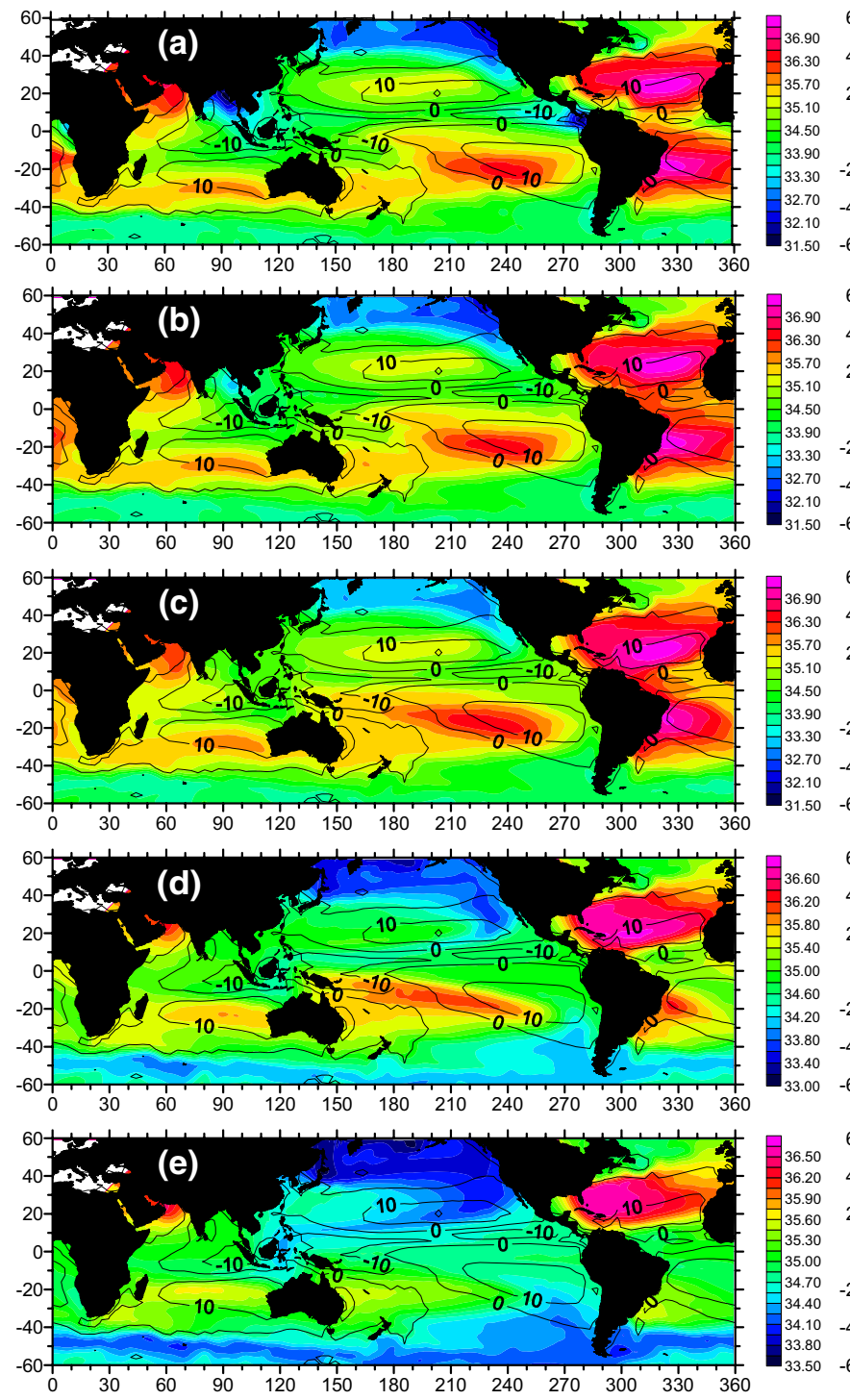

Fig. 1 Global climatologies of ocean salinity for 2004-2014 derived from Argo data at selected depths: a 5 m, b $50 \mathrm{~m}$, c $100 \mathrm{~m}$, d $200 \mathrm{~m}$, e $300 \mathrm{~m}$, f $400 \mathrm{~m}, \mathbf{g} 500 \mathrm{~m}, \mathbf{h} 600 \mathrm{~m}$, i $1000 \mathrm{~m}$, and j $1950 \mathrm{~m}$. Note

Hosoda et al. 2009). For the subsurface oceans, however, water masses formation through advection and convection/ subduction is mainly responsible for the salinity distribution. A careful comparison of the two maps suggests, however, that regions of maximum net $E-P$ are displaced systematically to the east of the SP centroids (see the contours overlaid on Fig. 1). This lateral displacement is believed to primarily result from the advection effect of the six subtropical gyres (note that the one in the North Indian Ocean is highly distorted by the continent and reverses seasonally with the monsoon cycle), so that salinity pattern resembles, to a large extent, the westward intensification feature of the ocean circulation. In the subsurface ocean, the formation of salinity maximum water in the North Atlantic is
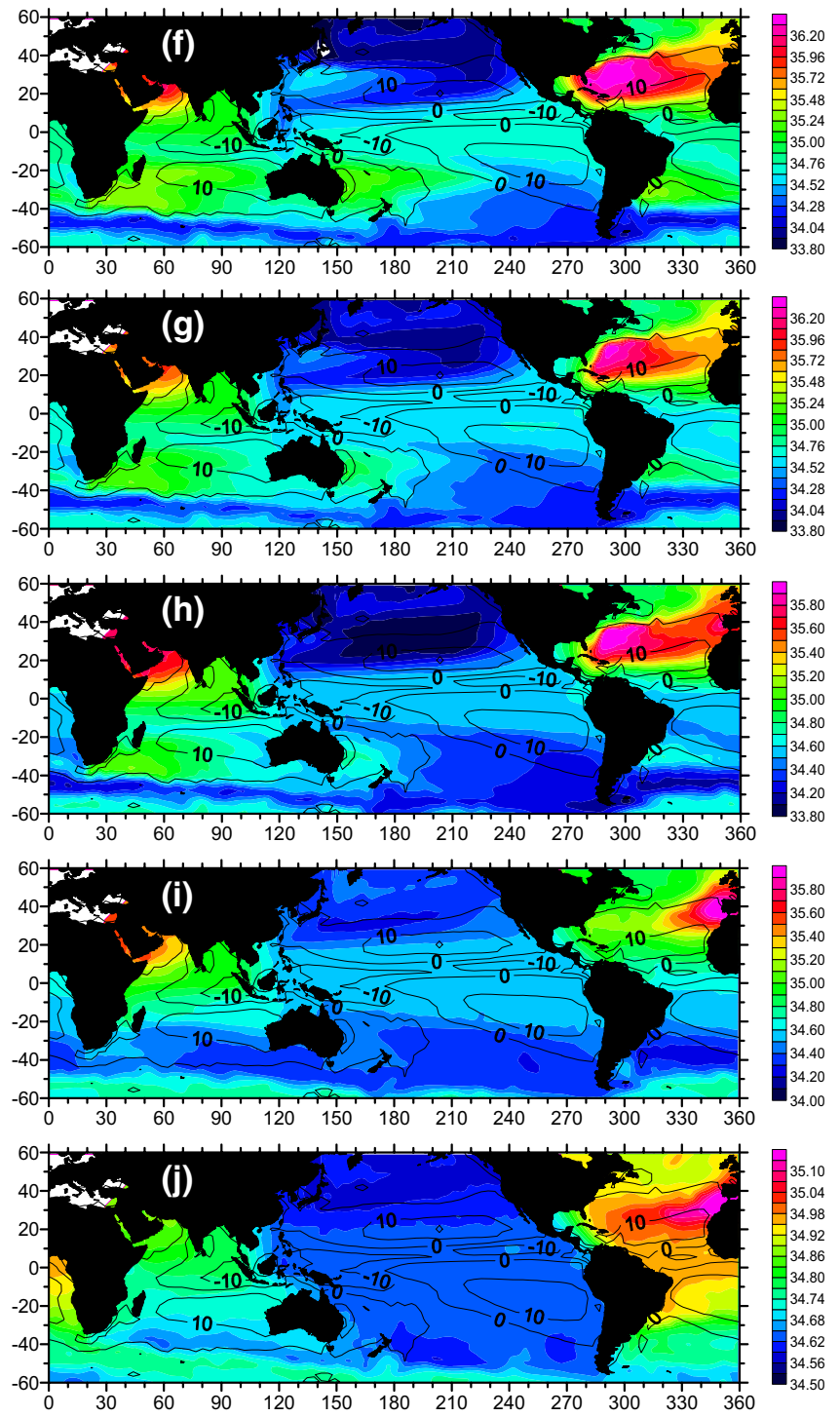

that the color scale (in psu) changes with depth. The $E-P$ contours replotted from e of Yu (2011) are also overlaid on each panel for comparison

investigated by Qu et al. (2013) using a simulated passive tracer and its adjoint. Their results reveal that most salinity maximum water in the North Atlantic comes from the northwestern part of the subtropical gyre, and direct contribution from the $E-P$ maximum region via the surface Ekman current is minor. It is also hypothesized that turbulent transport in the surface ocean is a crucial process for setting mixed layer characteristics, which spread into subsurface salinity maximum stratum (Busecke et al. 2014). These mechanisms largely remain valid until $\sim 600 \mathrm{~m}$ depth, below which the overall influence of the gyre flows (especially their eastern boundary currents) becomes very weak (e.g., Leaman et al. 1989). Therefore, the observed six-SP pattern in the global upper oceans is basically a 
layer-dependent balance between the six $E-P$ maxima with east preference and surface dominance, and the six subtropical gyres with west preference and subsurface dominance.

Another salient characteristic of the six SPs is the systematic westward migration of their centroids with respect to depth: all reaching the western boundaries of the oceans at about 200-600 m (see Fig. 1e-h, and also Table 1). Such a pattern is found to gradually disappear as going deeper, with only two SPs being evident at $1950 \mathrm{~m}$ depth in the North Atlantic and North Indian Ocean, respectively (Fig. 1j, as will be discussed in the following paragraph). In addition to the westward mass transport induced by mean circulations of the six gyres, the observed subtropical west preference of the six SPs is also partly a reflection of the systematic westward migration of mesoscale eddies which leads to remarkable westward mass entrainment in all latitude bands between $20^{\circ}$ to $40^{\circ}$ (see Fig. 3 in Zhang et al. 2014). And the layers of 200-600 m coincide with the maximum salinity anomaly which represents the core depths of the trapped eddies (see Fig. 2 in Dong et al. 2014). Busecke et al. (2017) used a suite of observationally driven model experiments to investigate the contribution of near-surface lateral eddy mixing to the subtropical surface salinity maxima in the global ocean. They found that the ratio of destruction by eddy mixing in the surface layer versus the surface forcing exhibits regional differences in the mean (from 10\% in the South Pacific to up to $25 \%$ in the south Indian), and the regional basins show seasonal and interannual variability in eddy mixing. These and our results suggest that the climatological ocean circulations may act as background "salt conveyors", meanwhile salt parcels can also be discretely entrained by numerous migrating eddies and swirls, the combined effects of which lead to the formation of six well-defined "salty pools" in the middle and western subtropical oceans, as also described by Schmitt and Blair (2015) as "a river of salt".

Further downward between 1000 and $2000 \mathrm{~m}$ depths, two major salinity maxima layers are located in the eastern North Atlantic and northern Indian Ocean (Fig. 1i, j). These saline intermediate waters are originated from high salinity outflows from the Mediterranean through Gibraltar Strait and from the Red Sea through Tiran Strait. The source of these high salinity waters is the surface inflows into these seas. High evaporation and lack of river discharge there persistently increases the salinity, thus dense water is continuously formed. When these saline waters flow back into the open ocean, they are dense enough to sink to a depth of $\sim 1000 \mathrm{~m}$ near the Gulf of Aden in the northern Indian Ocean, and of $\sim 2000 \mathrm{~m}$ near the Strait of Gibraltar in the eastern North Atlantic (Talley 2008).

Next, given the dominant east-west polarity of major salinity features at all depths, the layer-averaged climatological means of ocean salinity as a function of depth for different zonal bands as well as the global ocean are plotted in Fig. 2. Unlike the case of global mean ocean temperature which has a trend of monotonic downward decrease, its salinity counterpart is characterized by a two- extrema vertical structure: a well-defined maximum at $130 \mathrm{~m}$, and a less-well-defined minimum at approximately $800 \mathrm{~m}$ (see the thick black line in Fig. 2). For the twelve zonal bands, a dividing latitude of $\sim 45^{\circ}$ appears to separate the vertical distributions into two regimes for both hemispheres: the upper-saltier regime within $0-45^{\circ}$, and the upper-fresher regime beyond $45^{\circ}$, which remain largely true for the 0-500 m layers. For oceans below $\sim 1000 \mathrm{~m}$ depth, salinity values converge toward the global ocean and become nearly unified at $2000 \mathrm{~m}$ depth. Such vertical distributions imply that double or even multiple haloclines may exist in many areas of the global ocean. For the tropical and subtropical oceans, two coupled haloclines are formed immediately above and below the local salinity maximum around $100-150 \mathrm{~m}$, while for the extratropical regions, a single primary halocline at about $100 \mathrm{~m}$ is a common feature.

\section{Annual and semiannual amplitudes}

We first try to examine the penetrative behavior of seasonal salinity signals into the upper ocean. Figure 3 a shows the layer-averaged spectrum of salinity variability within the broad seasonal band. It is apparent that a two-mode structure centered at 6 and 12 months can be identified throughout the full range of Argo floats, suggesting that significant variations below the thermocline on annual and semiannual
Table 1 Centroids of the six well-defined "salty pools" at selected depths of the global upper oceans

\begin{tabular}{lllllll}
\hline Depth $(\mathrm{m})$ & N. Atlantic & S. Atlantic & N. Pacific & S. Pacific & N. Indian & S. Indian \\
\hline 5 & $325^{\circ} \mathrm{E}, 24^{\circ} \mathrm{N}$ & $327^{\circ} \mathrm{E}, 18^{\circ} \mathrm{S}$ & $187^{\circ} \mathrm{E}, 24^{\circ} \mathrm{N}$ & $235^{\circ} \mathrm{E}, 20^{\circ} \mathrm{S}$ & $60^{\circ} \mathrm{E}, 24^{\circ} \mathrm{N}$ & $91^{\circ} \mathrm{E}, 30^{\circ} \mathrm{S}$ \\
100 & $322^{\circ} \mathrm{E}, 22^{\circ} \mathrm{N}$ & $325^{\circ} \mathrm{E}, 16^{\circ} \mathrm{S}$ & $180^{\circ} \mathrm{E}, 21^{\circ} \mathrm{N}$ & $231^{\circ} \mathrm{E}, 18^{\circ} \mathrm{S}$ & $63^{\circ} \mathrm{E}, 28^{\circ} \mathrm{N}$ & $93^{\circ} \mathrm{E}, 27^{\circ} \mathrm{S}$ \\
200 & $309^{\circ} \mathrm{E}, 19^{\circ} \mathrm{N}$ & $326^{\circ} \mathrm{E}, 18^{\circ} \mathrm{S}$ & $161^{\circ} \mathrm{E}, 16^{\circ} \mathrm{N}$ & $212^{\circ} \mathrm{E}, 15^{\circ} \mathrm{S}$ & $60^{\circ} \mathrm{E}, 24^{\circ} \mathrm{N}$ & $90^{\circ} \mathrm{E}, 23^{\circ} \mathrm{S}$ \\
300 & $290^{\circ} \mathrm{E}, 33^{\circ} \mathrm{N}$ & $310^{\circ} \mathrm{E}, 32^{\circ} \mathrm{S}$ & $135^{\circ} \mathrm{E}, 29^{\circ} \mathrm{N}$ & $165^{\circ} \mathrm{E}, 23^{\circ} \mathrm{S}$ & $59^{\circ} \mathrm{E}, 24^{\circ} \mathrm{N}$ & $75^{\circ} \mathrm{E}, 20^{\circ} \mathrm{S}$ \\
400 & $292^{\circ} \mathrm{E}, 34^{\circ} \mathrm{N}$ & $310^{\circ} \mathrm{E}, 32^{\circ} \mathrm{S}$ & $135^{\circ} \mathrm{E}, 30^{\circ} \mathrm{N}$ & $159^{\circ} \mathrm{E}, 27^{\circ} \mathrm{S}$ & $60^{\circ} \mathrm{E}, 24^{\circ} \mathrm{N}$ & $31^{\circ} \mathrm{E}, 35^{\circ} \mathrm{S}$ \\
500 & $292^{\circ} \mathrm{E}, 34^{\circ} \mathrm{N}$ & $312^{\circ} \mathrm{E}, 30^{\circ} \mathrm{S}$ & $136^{\circ} \mathrm{E}, 30^{\circ} \mathrm{N}$ & $155^{\circ} \mathrm{E}, 31^{\circ} \mathrm{S}$ & $60^{\circ} \mathrm{E}, 24^{\circ} \mathrm{N}$ & $43^{\circ} \mathrm{E}, 36^{\circ} \mathrm{S}$ \\
600 & $292^{\circ} \mathrm{E}, 34^{\circ} \mathrm{N}$ & $312^{\circ} \mathrm{E}, 30^{\circ} \mathrm{S}$ & $136^{\circ} \mathrm{E}, 31^{\circ} \mathrm{N}$ & $155^{\circ} \mathrm{E}, 30^{\circ} \mathrm{S}$ & $56^{\circ} \mathrm{E}, 27^{\circ} \mathrm{N}$ & $39^{\circ} \mathrm{E}, 35^{\circ} \mathrm{S}$ \\
\hline
\end{tabular}


Fig. 2 Layer-averaged climatological mean (2004-2014) of ocean salinity as a function of depth for different zonal bands. The thick black line is for the global mean

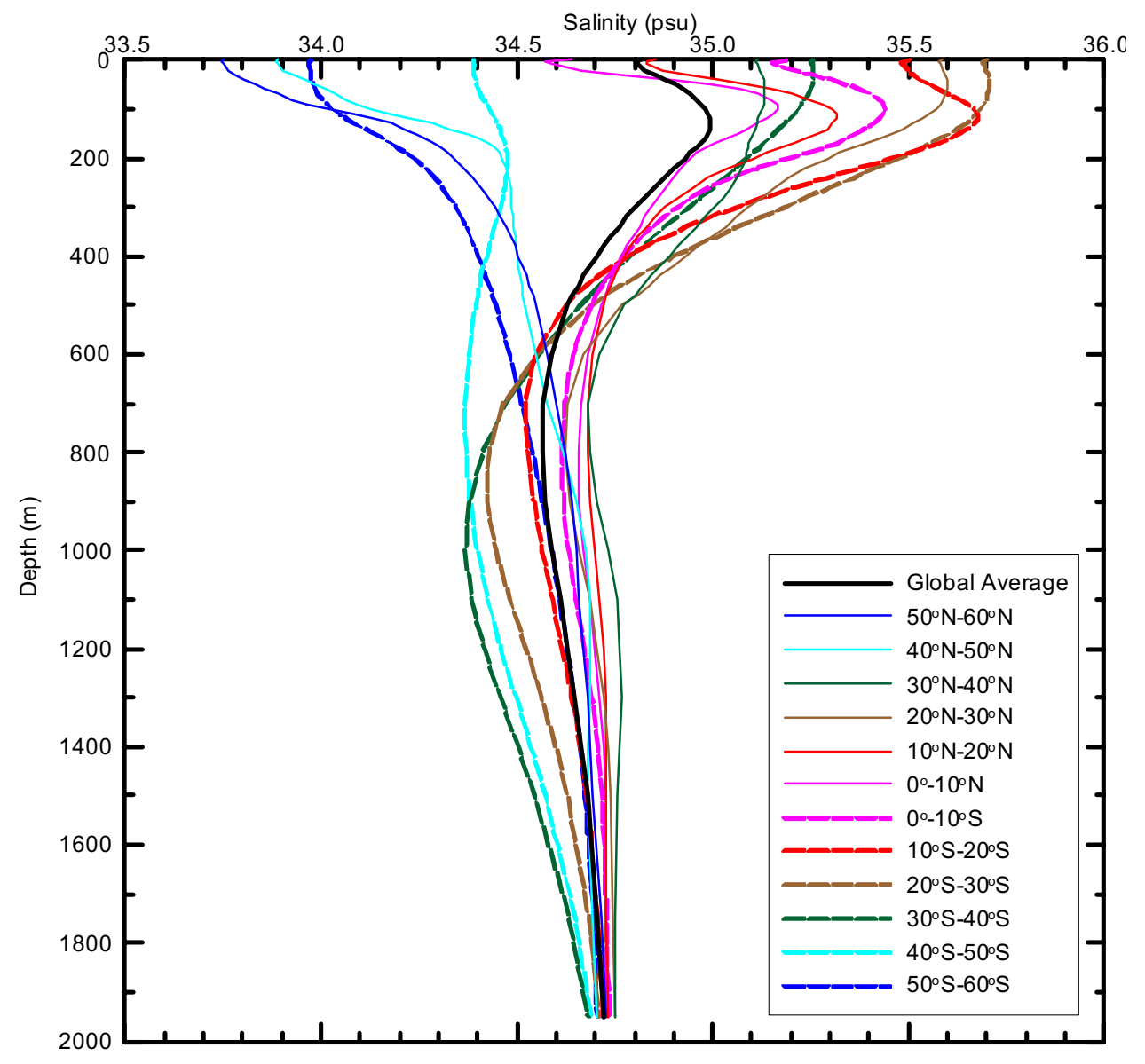

timescales exist not only for temperature (Hosoda et al. 2006; Chen and Wang 2016) but also for salinity. Obviously, the seasonal variability of salinity is dominated by the annual component. But surprisingly to some extent, the semiannual salinity signal can also penetrate effectively to a depth of $\sim 2000 \mathrm{~m}$. This can be quantitatively illustrated by plotting the spatially averaged seasonal amplitudes with respect to depth as shown in Fig. 3b. As expected, the two indices decline monotonically with depth. Globally, the annual component appears to be 2-3 times larger than the semiannual component within the mixed layer. It is also estimated that only $\sim 5.2$ and $\sim 2.6 \%$ of the surface strengths of seasonal salinity variability are left at $\sim 2000 \mathrm{~m}$ depth for the annual and semiannual harmonics, respectively. Locally, however, the vertical reduction behaviors of seasonal salinity signals are tremendously diverse.

The latitude-depth diagrams of longitudinally averaged annual and semiannual amplitudes of salinity variability for the global ocean are shown in Fig. 4a, b, respectively. Generally, the two distributions bear a similar shape with its major features located in the subsurface tropical ocean. A closer inspection reveals two core regions around $7^{\circ} \mathrm{N}$ and $7^{\circ} \mathrm{S}\left(7^{\circ} \mathrm{N}\right.$ and $\left.2^{\circ} \mathrm{S}\right)$ in the near-surface layer for the annual (semiannual) component, with the one in the northern hemisphere being much stronger. Note that the north/south asymmetry of the semiannual harmonic might be linked to the migration domain of the ITCZ. In fact, it was observed that the ITCZ favors $4^{\circ} \mathrm{N}$ in mean latitude, and meanders from $2^{\circ} \mathrm{S}$ to $8^{\circ} \mathrm{N}$ oceanwide (Chen and Lin 2005). Secondary maxima are identifiable in midlatitudes especially for the northern hemisphere. Unlike the basically horizontal features in sea temperature patterns of the upper $\sim 200 \mathrm{~m}$ zone (see Fig. 5 in Chen and Wang 2016), the latitudedepth diagrams of salinity seasonality are dominated by vertical structures with a meridional scale of some $10^{\circ}$. Since salinity functions in part as a tracer of water flow, these vertical structures might be indicative of the global meridional overturning circulation (MOC) system (Richardson 2008; Talley 2008), particularly for the intermediate layers between 200 and $2000 \mathrm{~m}$ where considerable temperature/salinity consistency is observed for both annual and semiannual signals (compare Figs. 4, 5 in Chen and Wang 2016). Our results add new evidence to previous findings that seasonal variations of the MOC can extend as deep as $1000 \mathrm{~m}$ due to zonal wind stress and the east-west slope of sea level (Kanzow et al. 2010; Liu et al. 2011). Meanwhile, one has to be aware of other possible contributing factors to the observed structures such as wind stress curl forcing for 
(a)
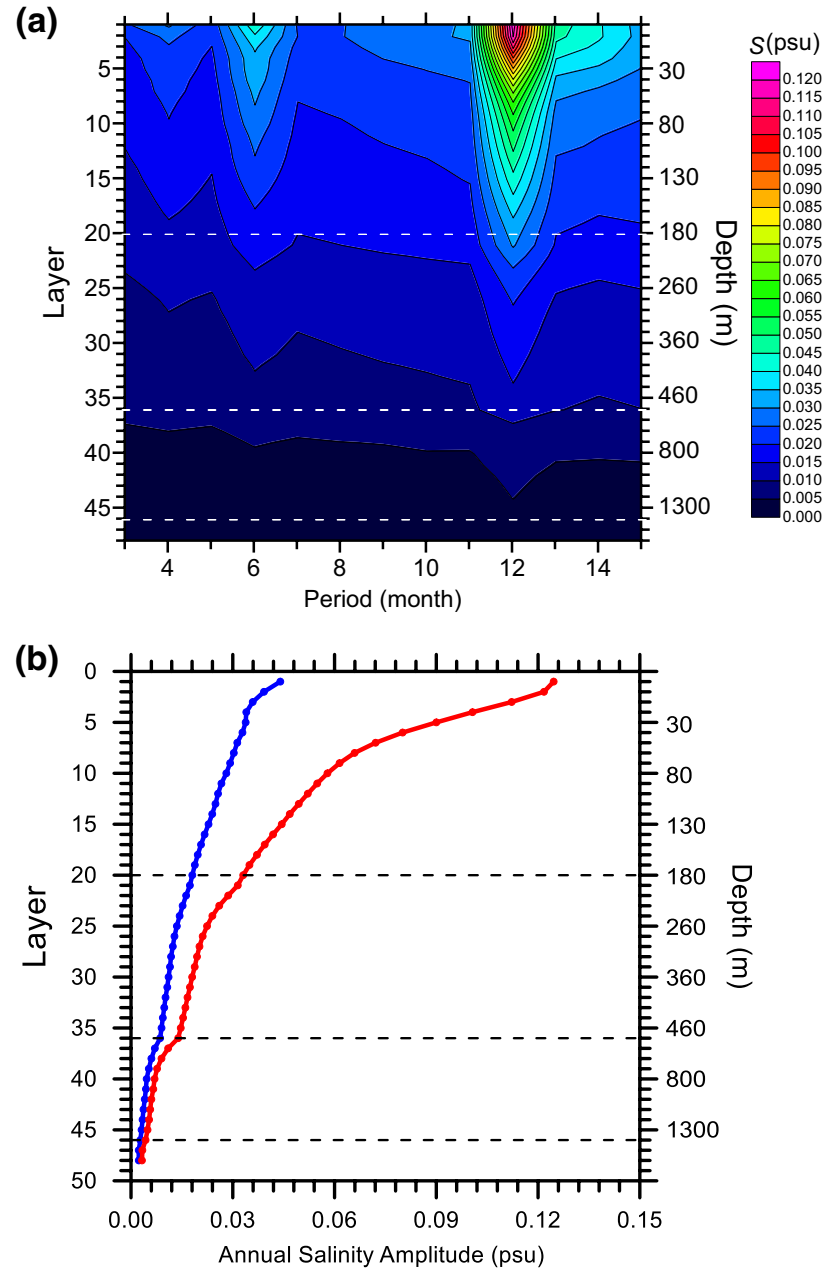

Fig. 3 a Period-depth diagram of layer-integrated spectrum of ocean salinity variability for the seasonal band derived from Argo data of 2004-2014. The color scale depicts the globally averaged harmonic amplitude of each depth layer. b Globally averaged annual (red) and semiannual (blue) amplitudes of ocean salinity as a function of depth. The horizontal dashed lines indicate bands of different vertical sampling intervals: $10 \mathrm{~m}$ (layers 2-20; $5 \mathrm{~m}$ for layer 1 but not shown), $20 \mathrm{~m}$ (layers 21-36), $100 \mathrm{~m}$ (layers 37-46), 200+ m (layers 47 and 48)

the mid-latitude part of the signal, and seasonal displacements of some western boundary currents.

The geographical distributions of the annual and semiannual harmonics of ocean salinity at selected depths are shown in Figs. 5 and 6, respectively. As summarized by $\mathrm{Yu}$ (2011), the dynamic mechanism behind the surface layer salinity seasonality can be understood in three aspects: huge annual fluctuation of annual river discharge along the northeastern coast of South America; large net $E-P$ dominance in the tropical convergence zones; and Ekman advection and vertical entrainment outside the tropics. In the near-surface layers between 0 and $100 \mathrm{~m}$, seasonal salinity variations are largely controlled by atmospheric forcings and river runoffs in the tropical oceans. Notably, the maximum seasonal variability of near-surface salinity is found along the northern coast of South America as a result of the joint effect of the Amazon and Orinoco Rivers with largest annual ranges in outflow volume in the world (Figs. 5a, 6a). Other major features of annual and semiannual cycles are associated with the ITCZ throughout the global oceans, the South Pacific Convergence Zone (SPCZ), the western boundary current zones in the North Atlantic (the Gulf Stream) and North Pacific (the Kuroshio), and the Asian monsoon region in northern Indian Ocean, as evidenced consistently in both amplitudes (Figs. 5a-c, 6a-c). These features are similar to those revealed by previous studies for the global surface and top layer salinity using various sources of data from satellites, profilers, and Argo floats (Boyer and Levitus 2002; Qu et al. 2014), with additional understanding that their general pattern basically retains for the entire mixed layer $(\sim 100 \mathrm{~m}$ in the tropical oceans as shown in Figs. 7, 9 of Chen and Yu 2015) despite the skin/near-surface differences caused by salinity stratification (Song et al. 2015).

Further downward between 200 and $300 \mathrm{~m}$ depths, zonal strips become evident in the tropical oceans (Figs. 5d, e, $6 \mathrm{~d}$, e). Judging from their spatial pattern in the Pacific Ocean, the origin of these features is likely to be linked to the equatorial current system including the South Equatorial Current (SEC) consisting of three branches situated around $0-8^{\circ} \mathrm{S}$ and $0^{\circ}-4^{\circ} \mathrm{N}$ within a depth of $0-200 \mathrm{~m}$, and $9^{\circ} \mathrm{S}-20^{\circ} \mathrm{S}$ which is much deeper and weaker, the North Equatorial Current (NEC) flowing westward between $9^{\circ} \mathrm{N}$ and $18^{\circ} \mathrm{N}$, while extending to a depth of $\sim 300 \mathrm{~m}$ (Wyrtki and Kilonsky 1984). Meanwhile, according to Izumo (2005), the Equatorial Undercurrent (EUC) has a meridional width of about $200-400 \mathrm{~km}$ centered on the equator along the thermocline between about 50 and $200 \mathrm{~m}$ depths across almost the whole length of the basin. Signatures of some of these currents are identifiable on the maps of annual and semiannual salinity amplitudes, since they are known to have a significant seasonal cycle which impacts the entire region (Meyers 1975; Wyrtki and Kilonsky 1984). Possible contributing mechanisms on the linkages between the observed seasonality and the dynamical variability may include changes in the velocity of the currents which directly modulate salt transport by the jets, and variability of the salinity in the source regions which propagate downstream seasonally.

It is worth to point out the generally inactive nature of salinity seasonality in the Pacific Ocean in contrast to the Atlantic and Indian Oceans, especially below $400 \mathrm{~m}$ depth (see Figs. $5 f-j, 6 f-j$ ). Contrary to the surface layer where dominant oceanic/atmospheric variabilities such as the warm pool, the ITCZ/SPCZ, and the El Niño/La Niña, as well as the equatorial and western boundary currents are 

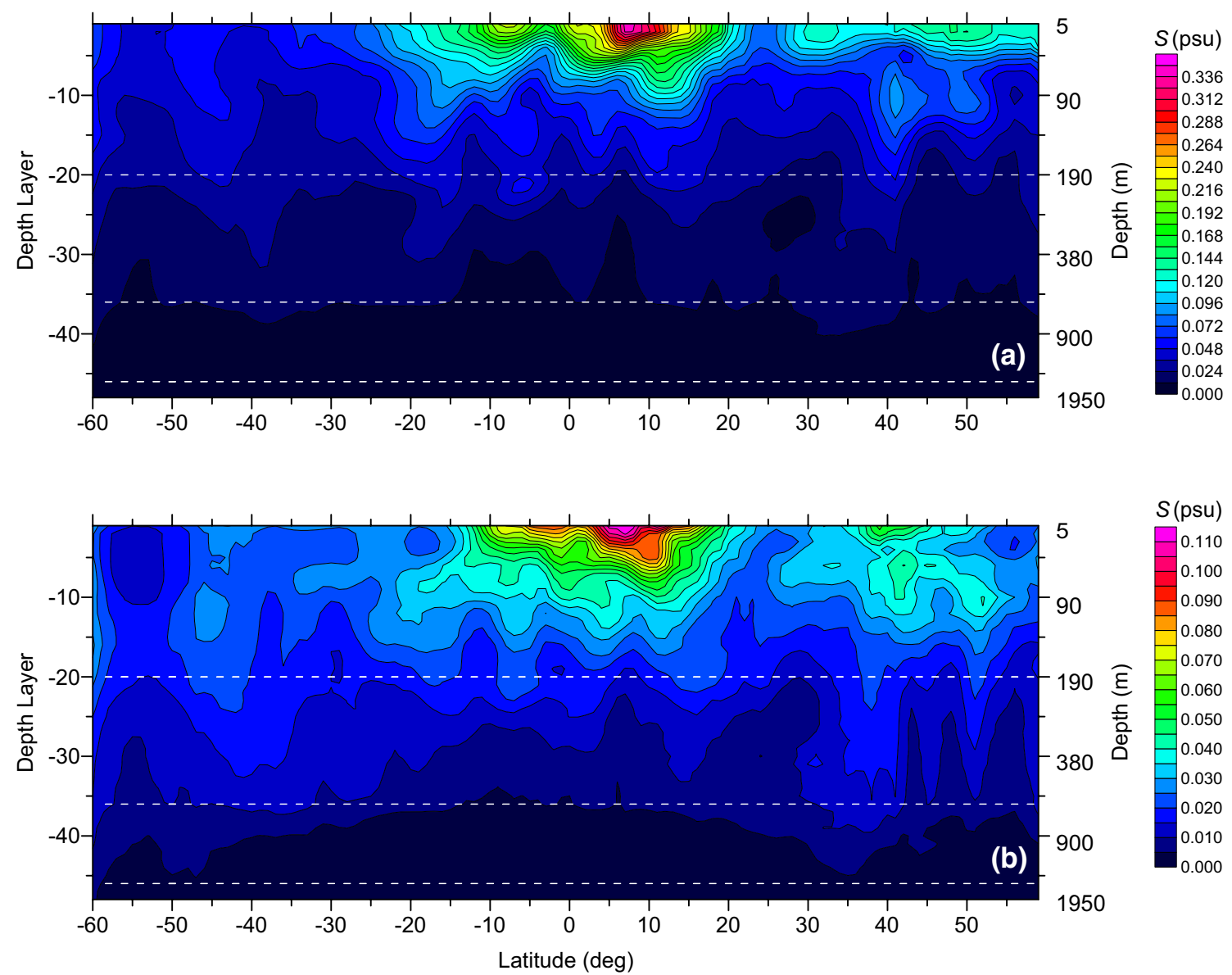

Fig. 4 Latitude-depth diagram of longitudinally averaged a annual and b semiannual amplitude of salinity variability for the upper global ocean. The horizontal dashed lines indicate bands of different

concentrated in the Pacific Ocean, the degree of subsurface dynamics in terms of salinity appears to be the highest in the Atlantic Ocean, followed by the Indian Ocean (mostly in the southern part). Again, reasons for the shift of dynamic regime from the Pacific to the Atlantic and Indian Oceans might be related to the global meridional overturning circulation. As a tracer of oceanic flow, salinity provides direct evidence that the Atlantic Ocean has the most important role to play in influencing the global climate via shallow-to-deep ocean vertical processes such as subduction and MOC (Chen and Tung 2014; Gordon and Giulivi 2014). Qu et al. (2013) demonstrate that a major portion $(\sim 70 \%)$ of salinity maximum water (as named SP here) is subducted to the Atlantic MOC at depths between 1000 and $3000 \mathrm{~m}$. Note that the North Atlantic is the most saline among the six SPs (Fig. 1e-h), being consistent with the conclusion of an Atlantic dominance of the global MOCs as a consequence of different relative strengths of the thermal and haline buoyancy forcings among the three Oceans (De Boer et al. 2008). Our result further suggests that such vertical sampling intervals: $10 \mathrm{~m}$ (layers $2-20 ; 5 \mathrm{~m}$ for layer 1 but not shown), 20 m (layers 21-36), 100 m (layers 37-46), 200+ (layers 47 and 48)

processes may also occur on mesoscales with a strong seasonal variation, and some of them are depth dependent (Figs. 5i, 6i).

\section{Annual and semiannual phases}

To further reveal some of the "hidden" characteristics of ocean salinity embedded in the time domain, the annual and semiannual phase maps corresponding to Figs. 5 and 6 are shown in Figs. 7 and 8, respectively. As far as the top $100 \mathrm{~m}$ of the annual phase is concerned (Fig. 7a-c), the general pattern appears to be mainly influenced by the atmospheric effect as it shows a certain geographical correlation with the annual phase of sea temperature (see Fig. 3a, b of Chen and Wang 2016). However, instead of being hemispherically opposite, the overall pattern of the annual salinity phase exhibits a kind of symmetric coherency between the two hemispheres possibly resulting from its close relationship with "permanent" ocean dynamics 

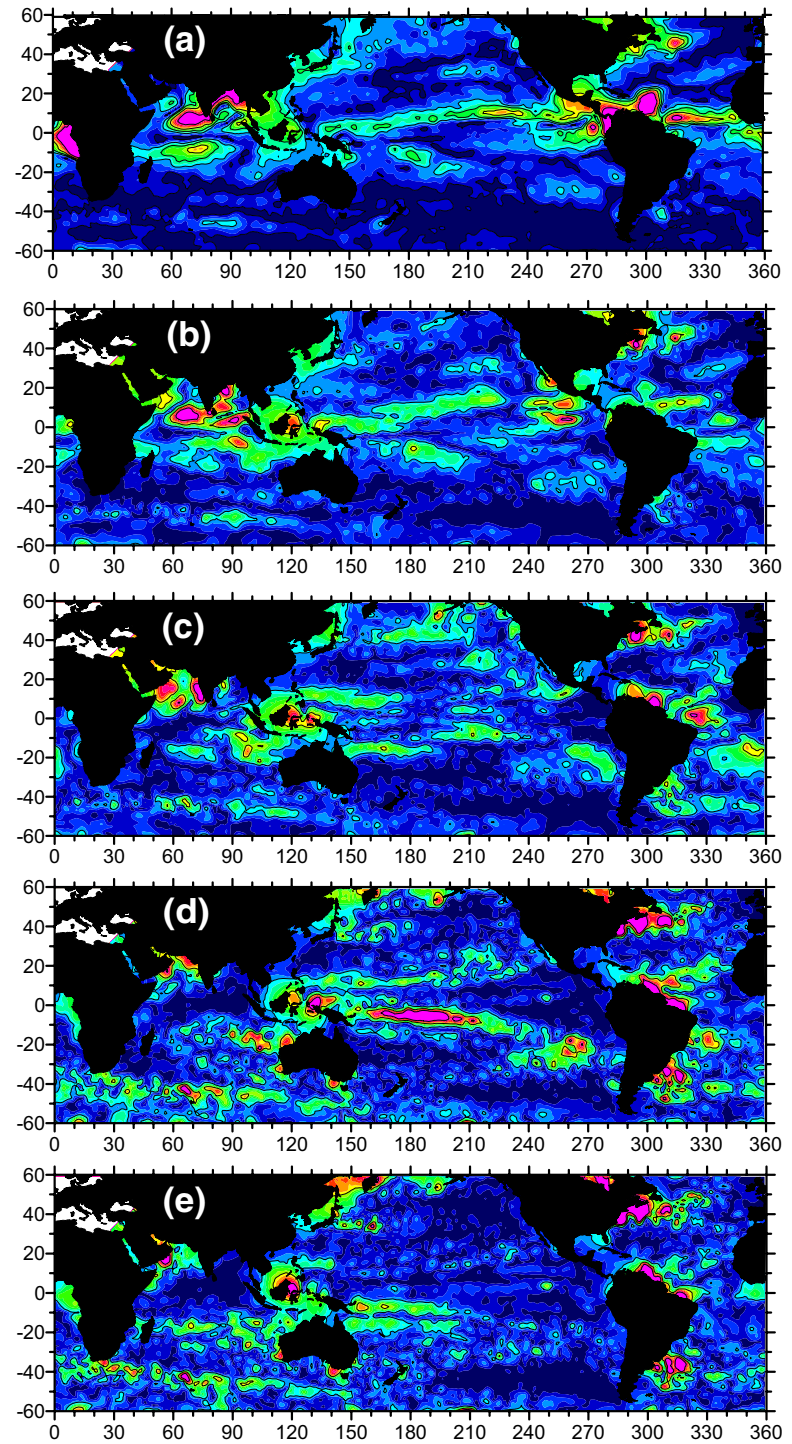
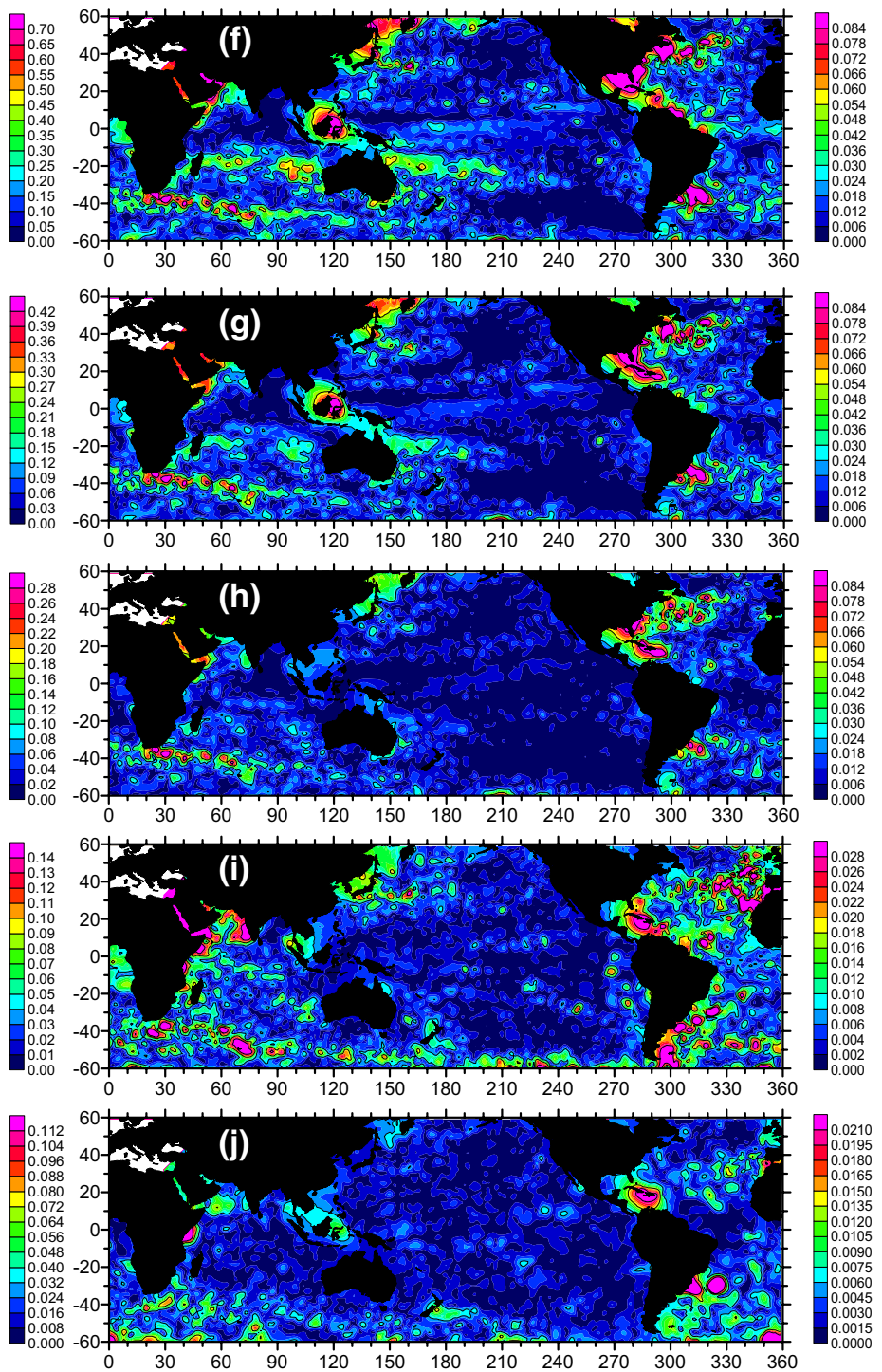

Fig. 5 Global maps of recovered annual amplitude (in psu) of ocean salinity variability at selected depths: a 5 m, b $50 \mathrm{~m}$, c $100 \mathrm{~m}$, d $200 \mathrm{~m}$, e $300 \mathrm{~m}, \mathbf{f} 400 \mathrm{~m}, \mathbf{g} 500 \mathrm{~m}, \mathbf{h} 600 \mathrm{~m}, \mathbf{i} 1000 \mathrm{~m}$, and j $1950 \mathrm{~m}$

such as gyres and eddies which are also hemispherically symmetric to a large extent. Meanwhile, the Antarctic Circumpolar Current region in the Southern Ocean is largely consistent in reaching the most saline season around November-December.

Like in the case of ocean temperature, the most spatially coherent feature of the annual salinity phase distribution is found in the tropical oceans between 200 and 600 m (Fig. 7d-h, see also Fig. 3c-d of Chen and Wang 2016). In fact, a large-scale westward annual progression of the saltiest season is observed in all three ocean basins (particularly in the Pacific Ocean as indicated by the white boxes in Fig. 7) with a leading timing along the equator. The tongue-shaped bending of thermohaline phases in the tropical oceans is highly consistent with the property of the first baroclinic mode of $\beta$-refracted annual Rossby waves, as Rossby waves of this kind are very common in this region (Chelton and Schlax 1996; Maharaj et al. 2009). The phase speed as a function of latitude is calculated to examine if the salient phase migration is compatible to the theoretical Rossby wave model. It confirms that a large portion of migration speeds correspond well to the first baroclinic mode as shown in Fig. 9 (see also Fig. 4 of Chen and Wang 2016). Again, the signal could barely be detected in the extratropical area. It should be mentioned, however, although systematically propagating signals of both temperature and salinity in the equatorial regions disappear below $\sim 600 \mathrm{~m}$ depth, Rossby-wave-like annual propagations can still be identified with ocean temperature along specific latitudes 

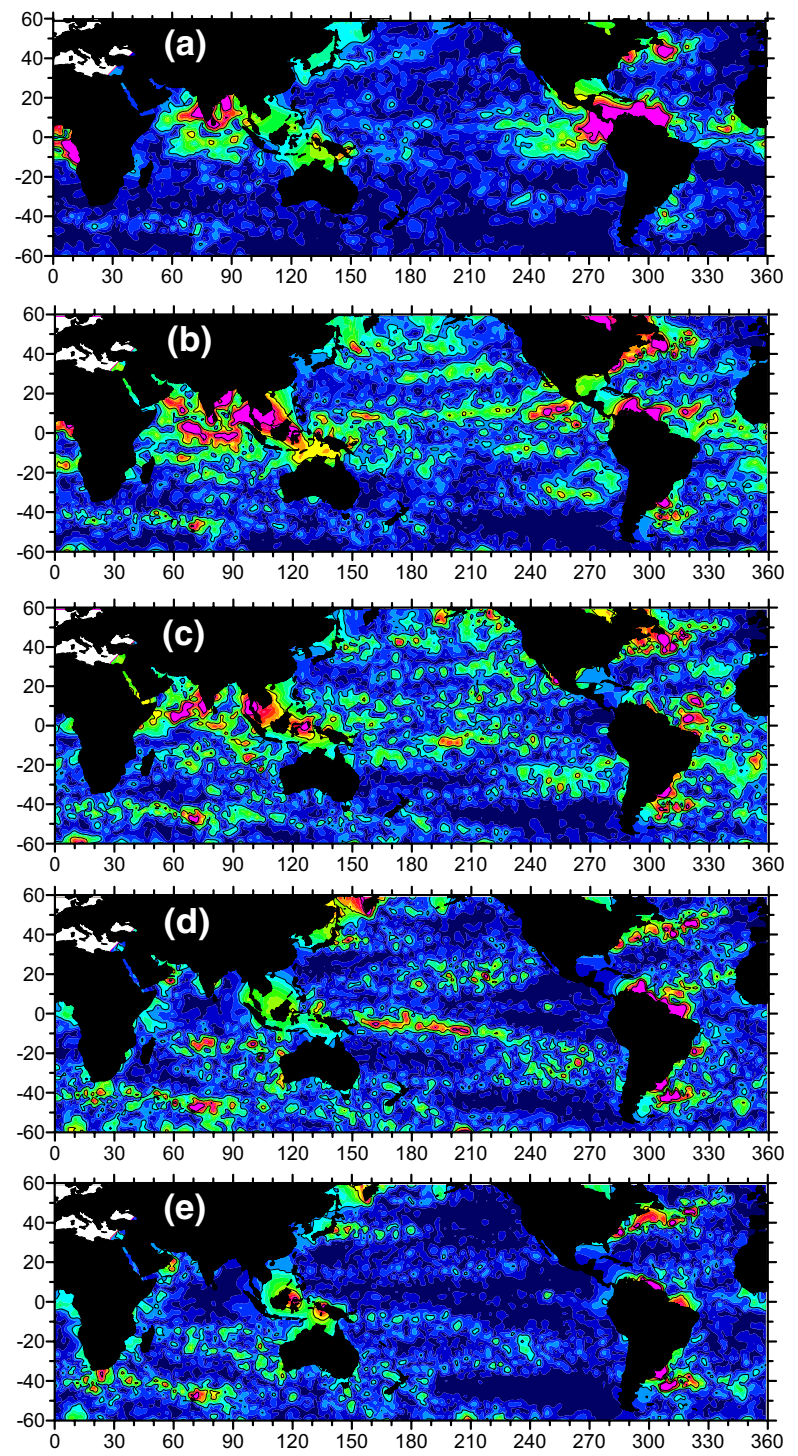
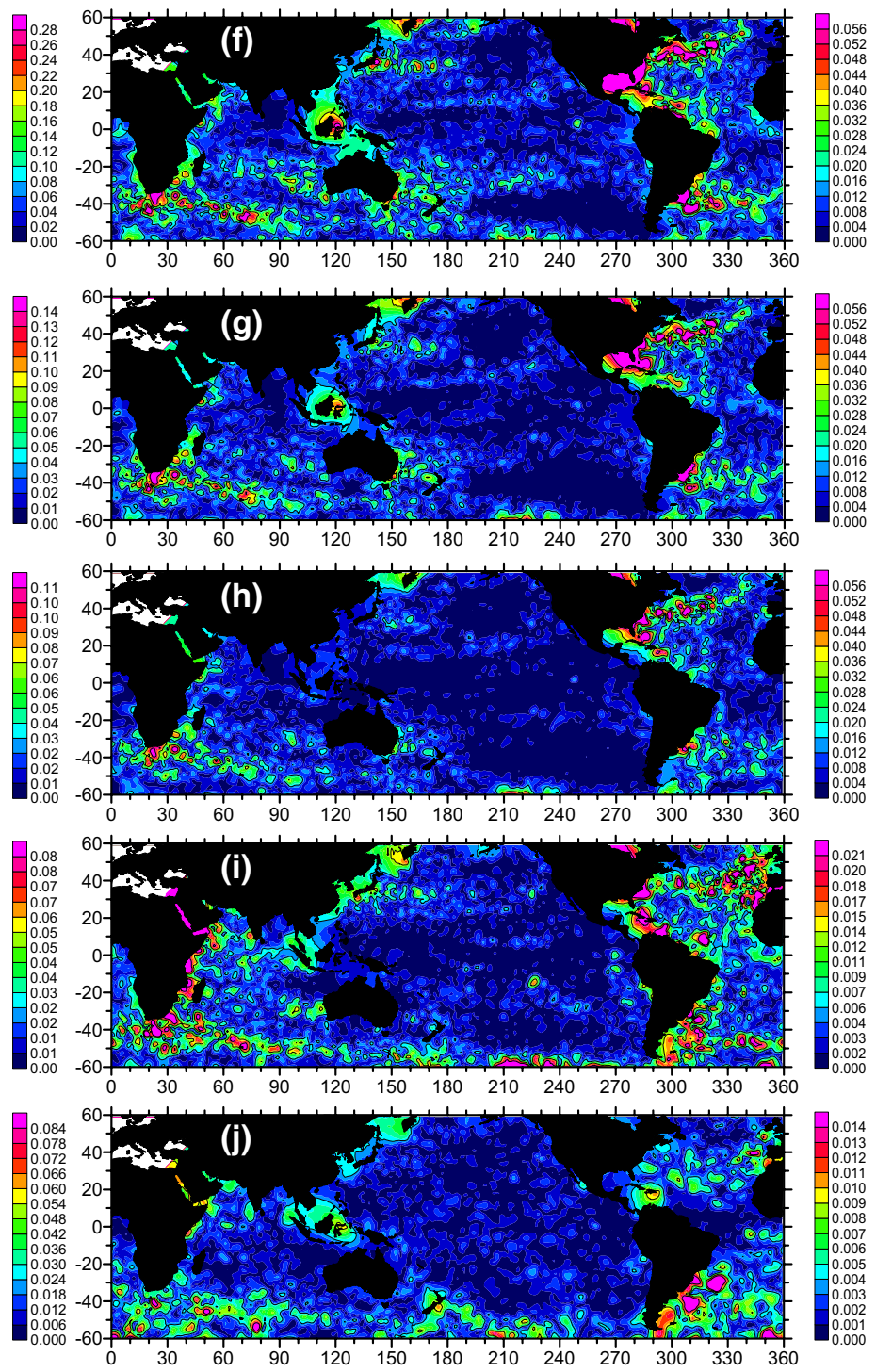

Fig. 6 Global maps of recovered semiannual amplitude (in psu) of ocean salinity variability at selected depths: a $5 \mathrm{~m}$, b $50 \mathrm{~m}$, c $100 \mathrm{~m}$, d $200 \mathrm{~m}, \mathbf{e} 300 \mathrm{~m}, \mathbf{f} 400 \mathrm{~m}, \mathbf{g} 500 \mathrm{~m}, \mathbf{h} 600 \mathrm{~m}$, i $1000 \mathrm{~m}$, and j $1950 \mathrm{~m}$

$\left(10.5^{\circ} \mathrm{N}, 17.5^{\circ} \mathrm{N}\right.$ and $\left.24.5^{\circ} \mathrm{N}\right)$ at the depth of $1200 \mathrm{~m}$, as reported by Hosoda et al. (2006).

The geographical dependency of the semiannual phase of ocean salinity is generally weak (Fig. 8). Zonal features associated with the Kuroshio and Gulf Stream as well as their extension regions, the equatorial current systems, the monsoonal areas in the Arabian Sea and the Bay of Bengal are identifiable within the top $\sim 100 \mathrm{~m}$ of the upper oceans (Fig. 8a-c). In particular, a prominent signature of the Wyrtki Jet is evident in the subsurface Indian Ocean, which corresponds to strong equatorial zonal flows that occur typically during boreal spring and fall at semiannual periods with an average speed of $-1.5 \mathrm{~m} / \mathrm{s}$ (Nagura and McPhaden 2010). Further downward, the phase pattern basically exhibits a random nature, except for the
SPCZ where a coherent feature can be marginally detected between $\sim 100-300 \mathrm{~m}$ (Fig. $8 \mathrm{~d}$, e). It is interesting to note the varying average size of the noisy semiannual phase patches from 200 to 2000 m (compare, e.g., Fig. 8e, j), reflecting the potential dominance of different dynamic activities such as mesoscale eddies and seasonal ventilations (see also similar plots for temperature in Fig. 3 of Chen and Wang 2016).

\section{Summary and conclusions}

Salinity measurements were insufficient to resolve the seasonal cycle in the interior of the global ocean (especially below $200 \mathrm{~m}$ ) until the Argo floats were massively 

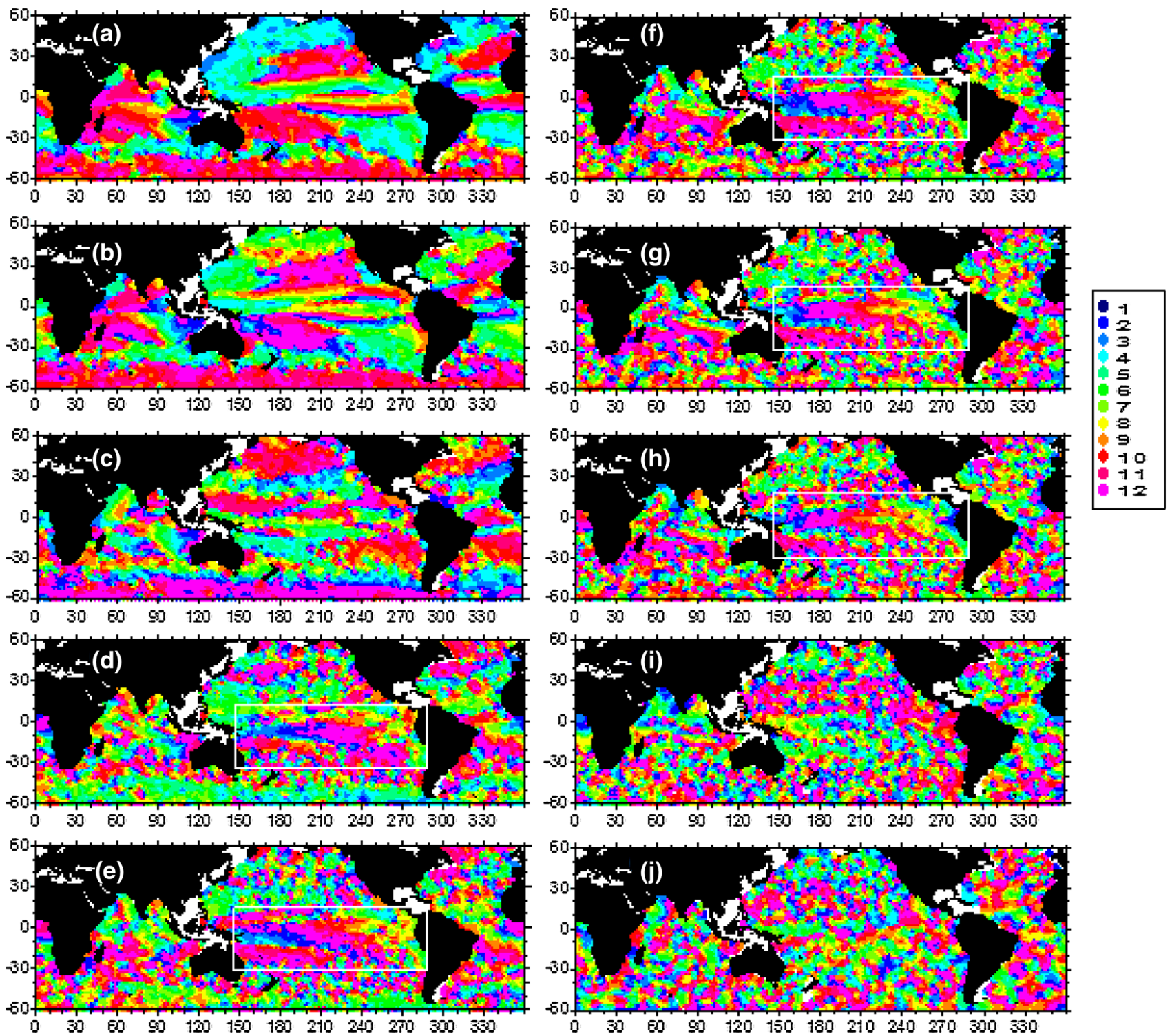

Fig. 7 Global maps of recovered annual phase of ocean salinity variability (in terms of peaking month) at selected depths: a $5 \mathrm{~m}, \mathbf{b} 50 \mathrm{~m}$, c $100 \mathrm{~m}, \mathbf{d} 200 \mathrm{~m}, \mathbf{e} 300 \mathrm{~m}, \mathbf{f} 400 \mathrm{~m}, \mathbf{g} 500 \mathrm{~m}, \mathbf{h} 600 \mathrm{~m}, \mathbf{i} 1000 \mathrm{~m}$, and j $1950 \mathrm{~m}$. White boxes indicate zones of annual phase lock

deployed early this century. In this research, the first decade of Argo-acquired salinity data are analyzed in the context of climatology and seasonality, yielding the following main results for the global upper oceans.

1. Analogous to the oceanic warm pools in nature and subtropical gyres in pattern, six well-defined "salty pools" are clearly revealed around $\pm 20^{\circ}$ in both hemispheres of the Pacific, Atlantic and Indian Oceans. They are found to tilt westward vertically from the sea surface to about $\sim 600 \mathrm{~m}$ depth, forming six saline tubes within the subsurface oceans. The surface distribution is likely to be a combined result of several well-known climatological processes: thermodynamic effects of net
$E-P$ control related to the tropical convergence zones, and the hydrodynamic effects of salty water subduction in gyre by downward Ekman pumping. While the westward eddy entrainment in conjunction with ocean circulations could be responsible for the observed tilt.

2. While potential temperature climatology decreases monotonically from surface to bottom in most places of the ocean, salinity usually has marked vertical structures. A dividing latitude of $\sim 45^{\circ}$ appears to separate the vertical distributions into two regimes for both hemispheres: the upper-saltier regime within $0-45^{\circ}$, and the upper-fresher regime beyond $45^{\circ}$. As far as the zonally averaged decadal means are concerned, the vertical distributions of ocean salinity can be further 

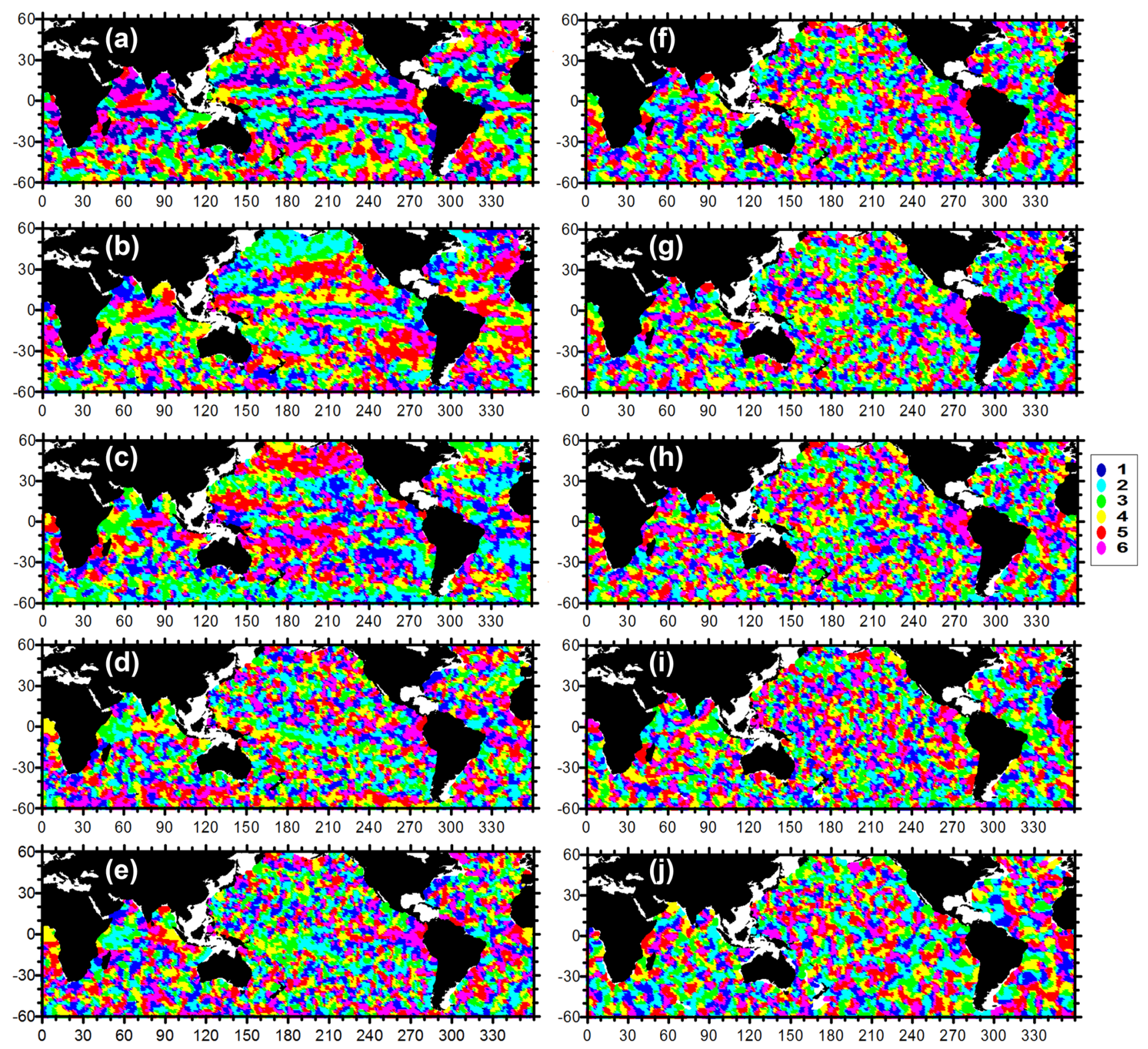

Fig. 8 Global maps of recovered semiannual phase of ocean salinity variability (in terms of peaking month) at selected depths: a $5 \mathrm{~m}, \mathbf{b} 50 \mathrm{~m}, \mathbf{c}$ $100 \mathrm{~m}, \mathbf{d} 200 \mathrm{~m}, \mathbf{e} 300 \mathrm{~m}, \mathbf{f} 400 \mathrm{~m}, \mathbf{g} 500 \mathrm{~m}, \mathbf{h} 600 \mathrm{~m}, \mathbf{i} 1000 \mathrm{~m}$, and j $1950 \mathrm{~m}$

classified into two categories: a double-halocline type (forming immediately above and below the local salinity maximum around 100-150 m depths) in the tropical and subtropical oceans, and a single primary halocline type (existing at about $100 \mathrm{~m}$ depth) in the extratropical oceans.

3. The salinity seasonal variability, identified by its annual and semiannual components, is found to effectively penetrate throughout the upper layers into a depth of $\sim 2000 \mathrm{~m}$, confirming that significant variations below the pycnocline on both annual and semiannual timescales exist not only for temperature but also for salinity. In contrast to the midlatitude dominance of temperature, however, seasonal variability of salinity in the oceanic mixed layer has a clear tropical dominance, implying totally different major forcing mechanisms (heat budget versus water cycle). Specifically, the geographical distributions of salinity seasonality are basically controlled by atmospheric $(E-P)$ and land (river discharge) effects within the upper $\sim 100 \mathrm{~m}$, by the equatorial current system between $\sim 100$ and $\sim 300 \mathrm{~m}$, and by the intermediate flow and meridional overturning circulation below $\sim 400 \mathrm{~m}$. 


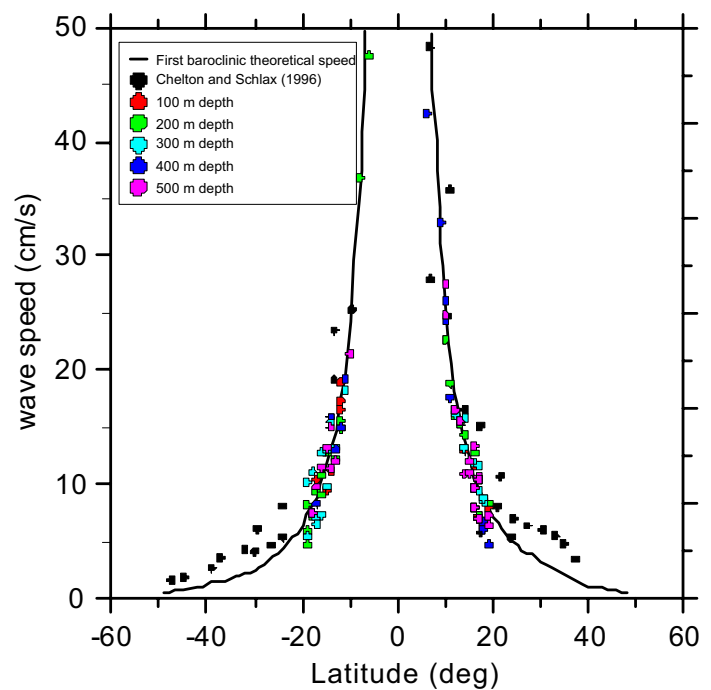

Fig. 9 The zonal phase speeds of annual Rossby waves at depths of $100,200,300,400$ and $500 \mathrm{~m}$, respectively. Also superimposed are the theoretical speeds derived from the first baroclinic mode (solid line) and the observed Rossby wave speeds from satellite sea level measurements (black dots; Chelton and Schlax 1996)

4. Signature of Rossby waves is clearly observed in the annual phase map of ocean salinity within 200-600 m depths in the tropical oceans, confirming a previous finding of similar nature with Argo-derived ocean temperature data. The consistency of westward temperature/salinity phase propagation originating from annual Rossby waves implies that a temperature/salinity covariation may exist around 300-400 m depth of the global ocean.

Acknowledgements This research was jointly supported by the Natural Science Foundation of China under Grants 61361136001, 41331172, 41527901 and U1606405, and the National Laboratory for Marine Science \& Technology under the Outstanding Scientist Project No. 2015ASTP-OS15 of the Ao-Shan Talents Program. Special thanks go to the China Argo Real-Time Data Center for providing us with the gridded Argo data product used in this study.

Open Access This article is distributed under the terms of the Creative Commons Attribution 4.0 International License (http:// creativecommons.org/licenses/by/4.0/), which permits unrestricted use, distribution, and reproduction in any medium, provided you give appropriate credit to the original author(s) and the source, provide a link to the Creative Commons license, and indicate if changes were made.

\section{References}

Bingham FM, Foltz GR, McPhaden MJ (2012) Characteristics of the seasonal cycle of surface layer salinity in the global ocean. Ocean Sci 8:915-929
Boutin J, Martin N, Yin X-B, Font J, Reul N, Spurgeon P (2012) First assessment of SMOS over open ocean: part-II-sea surface salinity. IEEE Trans Geosci Remote Sens 50:1662-1675. doi:10.1109/TGRS.2012.2184546

Boyer TP, Levitus S (2002) Harmonic analysis of climatological sea surface salinity. J Geophys Res 107:8006. doi:10.1029/2001JC000829

Boyer TP, Levitus S, Antonov JI, Locarnini RA, Garcia HE (2005) Linear trends in salinity for the World Ocean, 1955-1998. Geophys Res Lett 32. doi:10.1029/2004GL021791.

Busecke J, Gordon AL, Li Z, Bingham FM, Font J (2014) Subtropical surface layer salinity budget and the role of mesoscale turbulence. J Geophys Res 119:4124-4140

Busecke J, Abernathey RP, Gordon AL (2017) Lateral eddy mixing in the subtropical salinity maxima of the global ocean. J Phys Oceanogr 47:737-754

Chelton DB, Schlax MG (1996) Global observations of oceanic Rossby waves. Science 272:234-238

Chen G, Lin H (2005) Impact of El Niño/La Niña on the seasonality of oceanic water vapor: a proposed scheme for determining the ITCZ. Mon Wea Rev 133:2940-2946

Chen X, Tung K-K (2014) Varying planetary heat sink led to globalwarming slowdown and acceleration. Science 345:897-903

Chen G, Wang X (2016) Vertical structure of upper ocean seasonality: annual and semiannual cycles with oceanographic implications. J Climate 29:37-59

Chen G, Yu F (2015) An objective algorithm for estimating maximum oceanic mixed layer depth using concurrent temperature/ salinity data from Argo floats. J Geophys Res 120:582-595. doi:10.1002/2014JC010383

de Boyer Montégut C, Mignot J, Lazar A, Cravatte S (2007) Control of salinity on the mixed layer depth in the world ocean: 1. General description. J Geophys Res 112:C06011. doi:10.1029/2006JC003953

De Boer AM, Toggweiler JR, Sigman DM (2008) The Atlantic dominance of the meridional overturning circulation. J Phys Oceanogr 38:435-450

Delcroix T, Alory G, Cravatte S, Corrège T, McPhaden MJ (2011) A gridded sea surface salinity data set for the tropical Pacific with sample applications (1950-2008). Deep-Sea Res I 58:38-48

Dong C, McWilliams JC, Liu Y, Chen D (2014) Global heat and salt transports by eddy movement. Nat Commun 5:3294. doi: $10.1038 /$ ncomms 4294

Drucker R, Riser S (2014) Validation of Aquarius sea surface salinity with Argo: analysis of error due to depth of measurement and vertical salinity stratification. J Geophys Res 119:4626-4637

Durack PJ, Wijffels SE (2010) Fifty-year trends in global ocean salinities and their relationship to broad-scale warming. J Climate 21:5642-5656

Durack PJ, Wijffels SE, Matear RJ (2012) Ocean salinities reveal strong global water cycle intensification during 1950 to 2000. Science 336:455-458

Giglio D, Roemmich D, Cornuelle B (2013) Understanding the annual cycle in global steric height. Geophys Res Lett 40:4349-4354

Gordon AL, Giulivi CF (2014) Ocean eddy freshwater flux convergence into the North Atlantic subtropics. J Geophys Res 119:3327-3335. doi:10.1002/2013JC009596

Hasson AEA, Delcroix T, Dussin R (2013) An assessment of the mixed layer salinity budget in the tropical Pacific Ocean. Observations and modelling (1990-2009). Ocean Dyn 63:179-194

Hosoda S, Minato S, Shikama N (2006) Seasonal temperature variation below the thermocline detected by Argo floats. Geophys Res Lett 33:L13604. doi:10.1029/2006GL026070

Hosoda S, Suga T, Shikama N, Mizuno K (2009) Global surface layer salinity change detected by Argo and its implication for hydrological cycle intensification. J Oceangr 65:579-586 
Izumo T (2005) The equatorial undercurrent, meridional overturning circulation, and their roles in mass and heat exchanges during El Niño events in the tropical Pacific Ocean. Ocean Dyn 22:1499-1515

Kanzow T et al (2010) Seasonal variability of the Atlantic meridional overturning circulation at $26.5^{\circ} \mathrm{N}$. J Clim 23:5678-5698

Kolodziejczyk N, Gaillard F (2012) Observation of interannual variability of spiciness in the Pacific pycnocline. J Geophys Res 117:C12018. doi:10.1029/2012JC008365

Kolodziejczyk N, Gaillard F (2013) Variability of the heat and salt budget in the subtropical southeastern Pacific mixed layer between 2004 and 2010: spice injection mechanism. J Phys Oceangr 43:1880-1898

Lagerloef G, Colomb FR, Le Vine D, Wentz F, Yueh S, Ruf C, Lilly J, Gunn J, Chao Y, deCharon A, Feldman G, Swift C (2008) The Aquarius/SAC-D mission: designed to meet the salinity remotesensing challenge. Oceanography 21:68-81

Leaman K, Johns E, Rossby T (1989) The average distribution of volume transport and potential vorticity with temperature at three sections across the Gulf Stream. J Phys Oceanogr 19:36-51

Liu H, Zhang Q, Duan Y, Hou Y (2011) The three-dimensional structure and seasonal variation of the North Pacific meridional overturning circulation. Acta Oceanol Sin 30:33-42. doi:10.1007/ s13131-011-0117-4

Lorbacher K, Dommenget D, Niiler PP, Köhl A (2006) Ocean mixed layer depth: a subsurface proxy of ocean-atmosphere variability. J Geophys Res 111:C07010. doi:10.1029/2003JC002157

Maharaj A, Cipollini P, Holbrook N (2009) Multiple westward propagating signals in South Pacific sea level anomalies. J Geophys Res 114:C12016. doi:10.1029/2008JC004799

Meyers G (1975) Seasonal variation in transport of the Pacific North Equatorial Current relative to the wind field. J Phys Oceanogr $5: 442-449$

Moon J-H, Song YT (2014) Seasonal salinity stratifications in the near-surface layer from Aquarius, Argo, and an ocean model: Focusing on the tropical Atlantic/Indian Oceans. J Geophys Res 119:6066-6077. doi:10.1002/2014JC009969

Nagura M, McPhaden MJ (2010) Wyrtki Jet dynamics: seasonal variability. J Geophys Res 115:C07009. doi:10.1029/2009JC005922

Pawlowicz R (2013) Key physical variables in the ocean: temperature, salinity, and density. Nat Educ Knowl 4:13

Qu T, Gao S, Fukumori I (2013) Formation of salinity maximum water and its contribution to the overturning circulation in the North Atlantic as revealed by a global general circulation model. J Geophys Res 118:1982-1994. doi:10.1002/jgrc.20152

Qu T, Song YT, Maes C (2014) Sea surface salinity and barrier layer variability in the equatorial Pacific as seen from Aquarius and Argo. J Geophys Res 119:15-29. doi:10.1002/2013JC009375
Reverdin G et al (2007) Surface salinity measurements-COSMOS 2005 experiment in the Bay of Biscay. J Atmos Oceanic Technol 24:1643-1654

Reverdin $\mathrm{G}$ et al (2014) Validation of salinity data from surface drifters. J Atmos Oceanic Technol 31:967-983

Richardson PL (2008) On the history of meridional overturning circulation schematic diagrams. Prog Oceanogr 76:466-486

Riser SC, Ren L, Wong A (2008) Salinity in Argo: a modern view of a changing ocean. Oceanography 21:56-67

Riser SC et al (2016) Fifteen years of ocean observations with the global Argo array. Nature Clim Change 6:145-153

Roemmich D, Gilson J (2009) The 2004-2008 mean and annual cycle of temperature, salinity, and steric height in the global ocean from the Argo Program. Prog Oceanogr 82:81-100

Roemmich D, Johnson GC, Riser S, Davis R, Gilson J, Owens WB, Garzoli SL, Schmid C, Ignaszewski M (2009) The Argo program observing the global ocean with profiling floats. Oceanography 22:34-43

Schmitt RW, Blair A (2015) A river of salt. Oceanography 28:40-45. doi:10.5670/oceanog.2015.04

Singh A, Delcroix T, Cravatte S (2011) Contrasting the flavors of El Niño-Southern Oscillation using sea surface salinity observations. J Geophys Res 116:C06016. doi:10.1029/2010JC006862

Song YT, Lee T, Moon J-H, Qu T, Yueh S (2015) Modeling skinlayer salinity with an extended surface salinity layer. J Geophys Res 120:1079-1095. doi:10.1002/2014JC010346

Talley LD (2008) Freshwater transport estimates and the global overturning circulation: shallow, deep and throughflow components. Prog Oceanogr 78:257-303

Terray L, Corre L, Cravatte S, Delcroix T, Reverdin G, Ribes A (2012) Near-surface salinity as Nature's rain gauge to detect human influence on the tropical water cycle. J Climate 25:958-977

The CLIVAR Salinity Working Group (2008) What's next for salinity? Oceanography 21:82-85

Wyrtki K, Kilonsky B (1984) Mean water and current structure during the Hawaii-to-Tahiti Shuttle Experiment. J Phys Oceanogr $14: 242-254$

$\mathrm{Yu}$ L (2011) A global relationship between the ocean water cycle and near-surface salinity. J Geophys Res 116:C10025. doi:10.1029/2010JC006937

Yu L (2014) Coherent evidence from Aquarius and Argo for the existence of a shallow low-salinity convergence zone beneath the Pacific ITCZ. J Geophys Res 119. doi:10.1002/2014JC010030.

Zhang Z, Wang W, Qiu B (2014) Oceanic mass transport by mesoscale eddies. Science 345:322-324 